This item was submitted to Loughborough's Research Repository by the author.

Items in Figshare are protected by copyright, with all rights reserved, unless otherwise indicated.

\title{
Physical activity profile of old order Amish, Mennonite, and contemporary children
}

PLEASE CITE THE PUBLISHED VERSION

http://dx.doi.org/10.1249/MSS.0b013e3181b3afd2

PUBLISHER

Lippincott, Williams \& Wilkins (@The American College of Sports Medicine)

VERSION

AM (Accepted Manuscript)

LICENCE

CC BY-NC-ND 4.0

\section{REPOSITORY RECORD}

Esliger, Dale W., Mark S. Tremblay, Jennifer L. Copeland, Joel D. Barnes, Gertrude E. Huntington, and David R. Bassett. 2019. "Physical Activity Profile of Old Order Amish, Mennonite, and Contemporary Children". figshare. https://hdl.handle.net/2134/15452. 
This item was submitted to Loughborough's Institutional Repository (https://dspace.lboro.ac.uk/) by the author and is made available under the following Creative Commons Licence conditions.

\section{creative
commons}

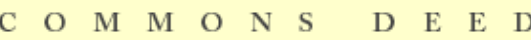

Attribution-NonCommercial-NoDerivs 2.5

You are free:

- to copy, distribute, display, and perform the work

Under the following conditions:

Attribution. You must attribute the work in the manner specified b the author or licensor.

Noncommercial. You may not use this work for commercial purposes.

No Derivative Works. You may not alter, transform, or build upon this work.

- For any reuse or distribution, you must make clear to others the license terms of this work.

- Any of these conditions can be waived if you get permission from the copyright holder.

Your fair use and other rights are in no way affected by the above.

This is a human-readable summary of the Leqal Code (the full license).

\section{Disclaimer 만}

For the full text of this licence, please go to: http://creativecommons.org/licenses/by-nc-nd/2.5/ 
Physical activity profile of Old Order Amish, Mennonite, and contemporary children

Running title: Modernity and physical activity in children

Dale W. Esliger ${ }^{1}$, Mark S. Tremblay, FACSM ${ }^{2}$, Jennifer L. Copeland ${ }^{3}$, Joel D. Barnes ${ }^{2}$,

Gertrude E. Huntington ${ }^{4}$, and David R. Bassett, Jr., FACSM ${ }^{5}$

${ }^{1}$ School of Sport and Health Sciences, University of Exeter, Exeter, Devon, United Kingdom

${ }^{2}$ Children's Hospital of Eastern Ontario Research Institute, Ottawa, Ontario, Canada

${ }^{3}$ Department of Kinesiology, University of Lethbridge, Lethbridge, Alberta, Canada

${ }^{4}$ Department of Anthropology (retired), University of Michigan, Ann Arbor, Michigan, USA

${ }^{5}$ College of Education, Health, and Human Sciences, University of Tennessee, Knoxville

Tennessee, USA

Funding: This research was supported by the Canadian Population Health Initiative of the

Canadian Institute for Health Information and the Charlie and Mai Coffey endowment in

Exercise Science at the University of Tennessee.

Address correspondence to:

Dale W. Esliger

Research Fellow

School of Sport and Health Sciences

University of Exeter

St. Luke's Campus

Heavitree Road

Exeter, EX1 2LU

United Kingdom

Email: d.esliger@ex.ac.uk

Tel: +44 (0) 1392262815

Fax: +44 (0) 1392264726 


\begin{abstract}
Purpose: This study explored the influence of modernity on the physical activity behaviors (e.g. intensity and timing) of children. Methods: Children aged 8-13 years living a traditional lifestyle (Old Order Amish; OOA n=68, Old Order Mennonite; OOM n=120) were compared with children living a contemporary lifestyle (rural; RSK n=132 and urban; USK n=93). Physical activity was objectively assessed for seven consecutive days using Actigraph 7164 accelerometers. Custom software was used to reduce the raw accelerometer data into standardized outcome variables. Results: On weekdays there were group differences in moderate physical activity between all lifestyle groups (OOA > OOM > USK > RSK). On the weekend, the group differences in moderate physical activity persisted between, but not within, lifestyle groups $(\mathrm{OOA}=\mathrm{OOM}>\mathrm{USK}=\mathrm{RSK})$. During school hours, all groups had similar activity and inactivity periods; however, they differed in magnitude with the OOA and OOM being both more sedentary and more active. Compared to in school, the OOA and OOM children had $44 \%$ lower sedentary time out of school compared to only $15 \%$ lower for RSK and USK children. Conclusions: Though cross-sectional, these data suggest that contemporary/modern living is associated with lower levels of moderate and vigorous intensity physical activity compared to lifestyles representative of earlier generations. Analyzing the physical activity and inactivity patterns of traditional lifestyle groups such as the OOA and OOM can provide valuable insight into the quantity and quality of physical activity necessary to promote health.
\end{abstract}

Key Words: MODERNITY, TECHNOLOGY, SEDENTARY, ENERGY EXPENDITURE, OBESITY, ACCELEROMETRY 


\section{Introduction}

Paragraph 1. Recent 7-day pedometer data from a nationally representative sample of 6,000 Canadian children and youth aged 5-19 years indicate that 73-91\% do not accumulate sufficient daily steps (5). Likewise, recent National Health and Nutrition Examination Survey (NHANES) data show that $58 \%$ of American children aged 6-11 and $92 \%$ of adolescents aged 12-19 are not meeting the recommended 60 minutes per day of physical activity (33). Although these data suggest that many children and youth are inactive, they do not allow us to determine if this was always the case or if physical activity has declined over time. Knowing how physically active children were when childhood obesity was rare may offer insight into obesity treatment and/or prevention. Unfortunately, longitudinal physical activity data on nationally representative samples of children and adolescents are lacking (17). However, data from questionnaire and time use studies may provide some insight into physical activity trends. For example, Canadian data show no change in leisure-time physical activity from 1981-1998 (7). These data are in line with more recent U.S data from the National Youth Risk Behavior Surveys that found no significant temporal trends in physical activity and physical inactivity between 1999 and 2005 (17).

Paragraph 4. In contrast to these trend data, evidence suggests that U.S. children and youth walk and cycle less for transportation with active trips to school decreasing from $20.2 \%$ in 1977 to $12.5 \%$ in 2001 (29). Further, U.S. time use data suggest that increased time spent in school, child care, studying, and reading have substantially decreased play and discretionary time from 1981 to 1997 (28). However, these conflicting data are based on proxy ecological evidence that does not take into account temporal changes in a certain domain (e.g., reductions in active commuting) which may be counter-balanced by opposing changes in another domain (e.g., increases in sports participation) (27). Moreover, it is generally felt that the major impact of technology on sedentary behavior was reasonably complete by the 1950 s due to the phasing out of heavy manual labor (11). Although further reductions in physical activity were expected due to advances in computer and communication technology, it was believed they would be much more subtle. Until more robust measures of physical activity are integrated into public health surveillance systems, our ability to monitor trends accurately will continue to be severely limited (18). 
Paragraph 5. In an effort to overcome the gap in historical trend data, Tremblay et al. (30) developed a unique model to assess the impact of modernity on activity levels in children. The authors reasoned that some cultures may preserve the inherently active lifestyle of earlier generations that preceded erosions to leisure-time and occupational physical activity and the childhood obesity epidemic. Their data show that Old Order Mennonite (OOM) children are leaner, stronger and more active than contemporary-living children from both rural and urban communities. Extending the model to look further back in time, Bassett et al. (2) found that Old Order Amish (OOA) children take more steps per day and have lower rates of overweight and obesity than contemporary-living children. Although much has been learned about the physical activity of Old Order Amish and Old Order Mennonite children, only the most basic variables have been explored to date (i.e., average moderate to vigorous physical activity (MVPA) per day and average steps per day). While quantitative information is useful for informing evidencebased physical activity guidelines (i.e., how much physical activity one should do to be healthy), it offers no insights into how one might go about achieving the recommended levels of physical activity (4).

Paragraph 6. To fully understand the quantity and quality of physical activity of these traditional groups, further work is needed to examine their activity patterns (i.e., specific intensities and timing of activity/inactivity) (1). Therefore, the purpose of this paper was to profile the physical activity and inactivity behaviors of Old Order Amish, Old Order Mennonite, and contemporary-living children as a means of assessing the influence of lifestyle. Hypothesis one was that group differences in physical activity would be evident (i.e., Amish > Mennonite > contemporary-living children). Hypothesis two was that group differences in physical inactivity would be evident (i.e., contemporary-living $>$ Mennonite > Amish children). Hypothesis three was that the timing (e.g., time of day and day of the week) of the physical activity of the Amish and Mennonite children would differ from that of the contemporary-living children.

\section{Methods}

Paragraph 7. The study employed an ex post facto (comparative) design whereby the cause(s) of group differences are assumed despite the lack of an experimental design. An overall sample of 474 children was drawn from four different groups: two living a traditional agrarian lifestyle (OOA and OOM) and two living a mainstream contemporary lifestyle (rural (RSK) and urban 
(USK)). The sampling procedures differed across the groups as follows: i) OOA: sampled entire population of 81 children (i.e., 100\% response rate); ii) OOM: randomized by family from a prescreened list with a total eligible population of 300 with an achieved response rate of $40 \%$; iii) RSK: self selected volunteers with a total population of 262 children and an achieved response rate of 59\%; USK: self selected volunteers with a total population of 178 and an achieved response rate of $62 \%$. As this study is based on secondary data analysis, each sample has been described in detail elsewhere $(1,2,30,31)$. In brief, the lifestyle of OOA and OOM children emphasizes simplicity and traditional values rather than progress and technology. Ownership of automobiles is not permitted. Farm tractors, telephones, and bicycles, are permitted, however, among the OOM. Farming and various labor trades are the preferred occupation. Children are educated in their own schools and formal education takes place only through to eighth grade. Therefore, we reasoned that the lifestyles of OOA and OOM children would be representative of typical physical activity behaviours of 100 and 60 years ago, respectively. The lifestyles of RSK children are typical of rural towns (pop<5000) whereas the lifestyles of USK children are typical of urban centers (pop>200,000) in Canada today.

Paragraph 8. As part of a larger battery of anthropometry and health-related fitness tests (peripheral to the present study), the 8-13 year old children had their height and body mass measured using a Health O Meter 402KL balance beam scale (Health O Meter Inc., Bridgeview, Illinois, United States). The attached height rod served as a stadiometer. The triceps skinfold was measured midway between the shoulder and elbow on the right arm using Harpenden C136 skinfold calipers (British Indicators, West Sussex, England). All anthropometric measures were measured using the same procedures and equipment for all samples.

Paragraph 9. Each child's physical activity was objectively measured for seven consecutive days via accelerometry. All pertinent data collection and analytical procedures related to the accelerometry portion of the study are described in Table 1 . The raw data were analyzed using custom software KineSoft version 2.0.95 (KineSoft, New Brunswick, Canada) to produce a series of standardized outcome variables similar to the procedures of Esliger et al. (8) (9). The main variables of interest were average minutes of sedentary, light, moderate, and vigorous intensity physical activity per day. Because the timing of activity and inactivity was of interest, the intensity variables were analyzed with the following time period groupings: weekday, weekend day, and hourly. Physical activity was measured using the same procedures and 
accelerometer model for all samples. In addition to parental consent, each child provided written assent to participate in the study. All procedures were approved by the Institutional Research Ethics Boards of the University of Saskatchewan and University of Tennessee.

\section{Statistical Analyses}

Paragraph 10. One-way ANOVAs were used to test for group differences in chronological age, month of data collection (i.e., seasonality), and accelerometer wear time. Subsequent analyses used MANCOVA models with chronological age and wear time as the covariate to determine group differences in anthropometric variables and physical activity and inactivity variables. Owing to the skewed distribution of the moderate and vigorous physical activity variables, these data were log transformed. All statistical tests were performed on the transformed data; however, in all cases the non-transformed means and standard deviations are presented. Paired samples t-tests were used to determine within group differences in the weekday versus weekend day physical activity variables. The influence of time of day on physical activity and inactivity was described visually via 24 hour x 7 day area plots for each group. Where appropriate, models used Bonferonni adjustments for post-hoc comparisons and alpha was set at $\mathrm{p}<0.05$. All analyses were performed using SPSS for Windows version 15.0 (SPSS Inc., Chicago, IL).

\section{Results}

Paragraph 11. The characteristics of the study sample are displayed by group in Table 2 . The sample size lost to technical failure of the accelerometers was $13.9,0.0,8.5$, and $2.7 \%$ for the OOA, OOM, RSK, and USK groups respectively. The traditional lifestyle groups were diligent in wearing their accelerometers and recording on/off times on their logs. As a result, the average sample size lost to participant non-compliance (i.e., not wearing the accelerometer for at least 10 hours per day for at least 4 weekdays and 1 weekend day) was $0.0,0.0,12.6$, and $13.1 \%$ for the OOA, OOM, RSK, and USK groups respectively. Impressively, 100\% of the OOA and OOM children had 7 days of valid data. All groups exceeded the daily wear time requirement with OOA children having the greatest average amount of wear time (14.5 hours per day) and RSK and USK children having the least (13.4 hours per day). The extra wear time was a result of the 1-2 hour earlier morning wake-up times of the traditional groups and their 30-70 minute earlier bed times.

Paragraph 12. The descriptive characteristics of the participants are displayed by group in 
Table 3. The samples are sex balanced; however, because the OOM children were older than the other groups, all further analyses controlled for age since it is well established that physical activity declines with age (22). OOA children were shorter than RSK children, weighed less than OOM and RSK children, and had lower BMI and triceps skinfolds than all other groups. Influence of Lifestyle on Physical Activity and Inactivity

Paragraph 13. Support for hypothesis one was evident on weekdays where there were group differences in moderate intensity physical activity (4-6.99 METs) between traditional lifestyle groups and contemporary lifestyle groups (OOA > OOM > USK > RSK; 90, 69, 58, 49 minutes per weekday respectively) (Figure 1). On the weekend, the group differences in moderate intensity physical activity persisted between, but not within, lifestyle groups $(\mathrm{OOA}=\mathrm{OOM}>$ USK = RSK; 55, 54, 36, 40 minutes per weekend day respectively) (Figure 2). There was relatively little vigorous physical activity ( $\geq 7 \mathrm{METs}$ ) accumulated on any day of the week. On weekdays OOA children accumulated a greater amount of vigorous physical activity compared to all other groups (Figure 1). Although the greater amount of vigorous physical activity in OOM children compared to RSK children was statistically significant, it is unlikely to have biological significance. With even fewer minutes of vigorous physical activity accumulated on the weekend by all groups, it was of little surprise that there were no differences between groups (Figure 2). Likewise, there were no group differences in inactivity behaviours between lifestyle groups on weekdays (Figure 1); however, on weekend days the USK children accumulated more sedentary time than any other group and the RSK children were more sedentary than the OOM children (Figure 2).

\section{Influence of Day of the Week and Time of Day on Physical Activity and Inactivity}

Paragraph 14. All within group differences between weekday and weekend day physical activity and inactivity were significant with the exception of the USK group for sedentary time and vigorous physical activity and the RSK group for light activity (Figures 1,2).

Paragraph 15. Plotting and visualizing the hourly physical activity behaviors by intensity and group revealed some interesting temporal trends (Figure 3). Focusing on school days (i.e., Monday-Friday from 08:00-15:00), it appears that the groups have similar patterns in physical activity and inactivity (i.e., they have the same activity and inactivity 'hotspots'). Comparing the two peak sedentary hours of the school day (i.e., 09:00-10:00 and 13:00-14:00) showed that OOA and OOM children spent on average, 50 of every 60 minutes during these two, one-hour 
blocks being sedentary compared to 40 of every 60 minutes for the contemporary children. Although being more sedentary during school hours, the OOA and OOM children were more active overall as evidenced by the higher amounts of moderate physical activity. In fact, both traditional groups had a pronounced tri-modal pattern of moderate physical activity, peaking during the morning commute (08:00-09:00), morning recess (10:00-11:00), and lunch (12:0013:00) hours (Figure 4). Notably, the hour during lunch break was on average the most active for all groups even when compared to free time on evenings and weekends. On average, OOA and OOM children spent 9 of every 60 minutes during these three, one-hour blocks being moderately active (compared to only 5 of every 60 minutes in the RSK and USK children). In fact, with the exception of the peak in moderate physical activity over the lunch break, it was difficult to discern clear peaks during the morning commute and/or the morning recess in the contemporary groups. The hourly contribution of vigorous physical activity was negligible across all groups over these three time periods.

Paragraph 16. Compared to the in-school time, OOA and OOM children's out-of-school time (i.e., Monday-Sunday from 15:00-21:00) showed a marked decline in sedentary time and an increase in time spent in moderate physical activity. This favorable shift was less pronounced in the RSK and USK children (Figure 3). Compared to in-school time, there was on average, $44 \%$ less sedentary time out of school in the OOA and OOM children amounting to 25 of every 60 minutes (27 minutes on weekend days) being spent sedentary during this 6-hour block. However, in the RSK and USK children sedentary time out of school was only $15 \%$ lower than in school time, amounting to 31 of every 60 minutes ( 35 minutes on weekend days) being spent sedentary during this 6-hour block. On weekend days, the RSK and USK children's sedentary time was fairly consistent with roughly half of every hour spent sedentary. Although OOA and OOM children were more active on Saturday, they were more sedentary on Sunday. Collectively these results support the hypothesis that the groups differ with respect to the day of the week and the time of the day they accumulated their physical activity and inactivity.

\section{Discussion}

Paragraph 17. The purpose of this study was to determine if differences in the lifestyles of children would be evident in their physical activity behaviour profile (e.g. intensity and timing). In an attempt to provide a 'window' to the past, we profiled the physical activity behaviours of 
Old Order Amish and Mennonite children known to differ in their use of modern conveniences such as labor saving technologies and sedentary, multimedia-based leisure pursuits. Though cross-sectional, these data suggest that contemporary/modern living is associated with lower levels of moderate physical activity compared to lifestyles representative of earlier generations (weekdays: OOA > OOM > USK > RSK; weekend days: OOA = OOM > USK = RSK). It is important to note that the physical activity levels of RSK and USK children (i.e., 51 and 58 minutes of MVPA per day) are comparable to other similarly analyzed datasets (e.g., NHANES, 60 minutes of daily MVPA; (33)). These comparative data imply that the differences between lifestyle groups are a result of OOA and OOM children being more active (i.e., 91 and 71 minutes of MVPA per day), not USK and RSK children being less active than typical children today. The fact that these traditional groups do not participate in organized sports or attend physical education classes suggests that the group differences are likely explained by differences in lifestyle-embedded physical activities such as farm and other manual chores, active commuting, and free play. This explanation seems logical when one considers the substantial contribution that lifestyle-embedded physical activities, also referred to as NEAT (non-exercise activity thermogenesis) (19), make towards total daily physical activity energy expenditure (32).

Paragraph 18. Those living a traditional agrarian lifestyle, most notably OOA children, accumulated large amounts of physical activity and met or exceeded most national physical activity guidelines, including on weekdays, Health Canada's $(12,13)$ recommendation of $\geq 90$ minutes per day. Therefore, the physical activity and inactivity profiles of OOA and OOM children may be a useful behavioral model for contemporary children to emulate. Perhaps the most remarkable difference between lifestyle groups was the consistently greater amount of physical activity and less time spent sedentary exhibited by the OOA and OOM children compared to the RSK and USK children in their discretionary time. Although the context or mode of this 'extra' physical activity is unknown, detailed information is available with respect to when/how this activity is accumulated. This 'how-to' information is crucial for the development of effective physical activity messages and programs that are necessary to promote healthy behavior change (4). For example, data from OOA children highlight the fact that the physical activity gap that exists for contemporary children could be made up by encouraging them to accumulate small amounts of physical activity intermittently throughout the day (e.g., during the morning commute, recess, lunch, after school commute and during the evening). 
These data, which are in agreement with those recently published by Riddoch and colleagues (25), show that making small changes in behaviors can add up to significant amounts of daily physical activity.

Paragraph 19. Living a lifestyle reminiscent of 100 years ago, OOA children accumulated on average 55 minutes more MVPA per weekday and 18 more minutes per weekend day compared to contemporary children. The 'extra' time spent being active in OOA children was significant and likely contributed to their low levels of overweight and obesity $(2,31)$. Unfortunately information about the mode and/or context of the physical activity is unknown; however, it is likely that agricultural chores contributed to the higher activity levels in the OOA and OOM children. Based on conservative estimates (i.e., using $4 \mathrm{kcal} \cdot \mathrm{kg}^{-1} \cdot \mathrm{hr}^{-1}$ ), this translates to an activity energy expenditure deficit of $124 \mathrm{kcal}$ per weekday and $51 \mathrm{kcal}$ per weekend day for the contemporary children. All else being equal, if the energy imbalance was maintained over the long term the contemporary children would be at risk of gaining $\sim 5 \mathrm{~kg}$ of fat per year (assuming that $7700 \mathrm{kcal}$ leads to an average of $1 \mathrm{~kg}$ weight gain as fat). This energy gap is similar to that found by Wang et al. (35) who suggested that consistent behavioral changes (i.e., reduced energy intake and/or increased energy expenditure) averaging 110 to $165 \mathrm{kcal} /$ day may be sufficient to counterbalance the energy gap in children. Unfortunately, maintaining energy balance in a modern world is difficult since the behavioral processes that evolved in order to ensure our survival are still intact. That is, people still eat when food is available and 'rest' when physical activity is not required. The problem is, food is nearly always available and physical activity is seldom required $(3,24)$.

Paragraph 20. Although OOA and OOM children were more active than contemporary-living children regardless of the day, on weekdays both groups spent similar amounts of time being sedentary. There were however, clear differences in how sedentary time was accumulated with group differences evident on weekend days. This is an important finding as there is mounting literature linking overall sedentary time and its pattern of accrual to health risks $(10,14,15,23)$. For example, on Sundays virtually all OOA and OOM children attend church. However, unlike the active commute to school, children travel to church with their families via horse and buggy and then sit through a service lasting two or more hours. These religious observances are easily discernable as sedentary bouts in Figure 3 when the activity profile on Saturday is compared to Sunday. No such clearly demarcated bout of sedentary time was found for the contemporary 
groups on Sunday. The notion that religious observance can have an impact on the accrual of physical activity and sedentary time has been studied before. Kahan (16) found that in a group of Jewish adolescents, those most likely to observe the Sabbath and attend a synagogue accrued less MVPA and less sedentary time compared to the less observant. Another contributing factor to the relatively large amounts of sedentary time during the school day relates to the fact that OOA and OOM children are educated in one-room school houses with limited space for moving around both during and between lessons. In contrast, contemporary children attend relatively large schools and often change classrooms between lessons and may have physical education classes scheduled throughout the school day. Cohen and colleagues (6) recently showed that the indoor square footage of a school can contribute 4 and 16\% to the light and MVPA of adolescent girls respectively.

Paragraph 21. A strength of this study was the use of objective measurements of physical activity (26). Another strength is the detailed analysis of the accelerometry data in terms of intensity and temporality. However, there are limitations to accelerometry, most notably, their inability to assess lifting and carrying activities, cycling, water-based activities, and the general lack of contextual information relating to activity mode and/or location/domain (21). For example, the fact that waist mounted accelerometers do not measure cycling could have limited the true quantification of MVPA in the OOM, RSK, and USK children all of whom ride bicycles; whereas the OOA children are disallowed. This explanation may partly explain the relatively high amounts of MVPA in the OOA children compared to the OOM children; however, one cannot forget the fact that OOM farms and homesteads are allowed some labor mechanization (e.g., tractors). Unfortunately no information was collected on activity mode. Although attempts were made to control for the month of data collection, seasonal differences were not specifically measured. In addition, specific information was not collected regarding school start and end times, recess, or lunch. Another limitation was that selection bias could not be ruled out due to the non-random nature of the sample. Although virtually all OOA children were measured, less than half of the OOM children were sampled; however, it is unlikely that the OOM children are at risk of physical activity related non-response bias as it was the most technologically conservative families that declined to participate. In contrast, the self-identifying process of contemporary school selection likely resulted in schools participating that were very supportive of physical activity. We are confident that, if anything, these limitations work to disprove our 
hypotheses and therefore strengthen our findings. Finally, it should be noted that this study included only children in technologically conservative Amish and Mennonite communities. Therefore, these results should not be generalized to other less conservative religiocultural communities where fewer families farm, and modern technology is more prevalent, as physical activity is likely to be lower in these groups.

\section{Conclusion}

Paragraph 22. Though cross-sectional, these data suggest that contemporary/modern living is associated with lower levels of moderate and vigorous intensity physical activity compared to lifestyles representative of earlier generations. Analyzing the physical activity and inactivity patterns of traditional lifestyle groups such as the OOA and OOM can provide valuable insight into the quantity and quality of physical activity necessary to promote health. Future work in this area should address differences in how children fractionalize (i.e., accumulate in bouts) their physical activity and inactivity and the impact these behaviors have on health.

\section{Acknowledgements}

The authors express their appreciation to all the children who participated in this study and to David Luthy for his assistance and guidance with the Amish community and Levi Frey for his assistance with the Mennonite community. This research was supported by the Canadian Population Health Initiative of the Canadian Institute for Health Information and the Charlie and Mai Coffey endowment in Exercise Science at the University of Tennessee.

\section{Conflict of Interest}

The authors declare no conflict(s) of interest. The results of the present study do not constitute endorsement by ACSM. 


\section{Figure Captions}

Figure 1. Mean minutes per weekday of sleep, sedentary, light, moderate, and vigorous intensity physical activity, by group

* significantly different from all other groups; ${ }^{\dagger}$ significantly different from RSK; \# indicates no within group difference between weekday and weekend day on the given variable; $\mathrm{P}<0.05$ Notes: i) means are adjusted based on age and wear time covariates; ii) both moderate and vigorous physical activity are scaled according to the secondary y-axis; iii) although statistical analyses were performed on log transformed moderate and vigorous physical activity variables, non-transformed data are presented; iv) error bars represent standard error

Figure 2. Mean minutes per weekend day of sleep, sedentary, light, moderate, and vigorous intensity physical activity, by group *significantly different from all other groups; ${ }^{\dagger}$ significantly different from RSK; ${ }^{\dagger}$ significantly different from RSK and USK; \# indicates no within group difference between weekday and weekend day on the given variable; $\mathrm{P}<0.05$

Notes: i) means are adjusted based on age and wear time covariates; ii) both moderate and vigorous physical activity are scaled according to the secondary y-axis; iii) although statistical analyses were performed on log transformed moderate and vigorous physical activity variables, non-transformed data are presented; iv) error bars represent standard error

Figure 3. Group differences in intensity-specific physical activity profiles ( 7 days $x 24$ hours) Note: White areas of the figure represent sleep time while the colored areas signify traffic light labeling of physical activity intensity. The sedentary activity is colored red to give the message to stop the behavior, light activity is colored yellow to give the message to be cautious of too much light activity, and both moderate and vigorous activity are colored green to give the message that these are positive behaviors.

Figure 4. Group differences in weekday moderate to vigorous physical activity (hour $\mathrm{x}$ hour)

Note: Table 1 cites two references not mentioned in the body of the article; Trost et al. (34) and Mattocks et al. (20). 


\section{References}

1. Bassett DR. Physical activity of Canadian and American children: a focus on youth in Amish, Mennonite, and modern cultures. Appl Physiol Nutr Metab. 2008;33(4):831-5.

2. Bassett DR, Jr., Tremblay MS, Esliger DW, Copeland JL, Barnes JD, Huntington GE. Physical activity and body mass index of children in an old order Amish community. Med Sci Sports Exerc. 2007;39(3):410-5.

3. Bellisari A. Evolutionary origins of obesity. Obes Rev. 2008;9(2):165-80.

4. Brawley LR and Latimer AE. Physical activity guides for Canadians: messaging strategies, realistic expectations for change, and evaluation. Can J Public Health. 2007;98 Suppl 2:S170-S184.

5. Cameron C, Wolfe R, Craig CL. Physical activity and sport: encouraging children to be active. 2007. Ottawa, ON, Canadian Fitness and Lifestyle Research Institute.

6. Cohen D, Scott M, Wang FZ, McKenzie TL, Porter D. School design and physical activity among middle school girls. J Phys Act Health. 2008;5(5):719-31.

7. Eisenmann JC, Katzmarzyk PT, Tremblay MS. Leisure-time physical activity levels among Canadian adolescents, 1981-1998. J Phys Act Health. 2004;1(2):154-162.

8. Esliger DW, Copeland JL, Barnes JD, Tremblay MS. Standardizing and optimizing the use accelerometer data for free-living physical activity monitoring. J Phys Act Health. 2005;2(3):366-83.

9. Esliger DW and Tremblay MS. Physical activity and inactivity profiling: the next generation. Can J Public Health. 2007;98 Suppl 2:S195-S207.

10. Hamilton MT, Hamilton DG, Zderic TW. Role of low energy expenditure and sitting in obesity, metabolic syndrome, type 2 diabetes, and cardiovascular disease. Diabetes. 2007;56(11):2655-67.

11. Haskell WL. Physical activity, sport, and health: toward the next century. Res $Q$ Exerc Sport. 1996;67(3 Suppl):S37-S47.

12. Health Canada and the Canadian Society for Exercise Physiology. Canada's physical activity guide for children. Cat.No.H39-611/2002-2E. 2002. Ottawa, ON, Minister of Public Works and Government Services Canada.

13. Health Canada and the Canadian Society for Exercise Physiology. Canada's physical activity guide for youth. Cat.No.H39-611/2002-1E. 2002. Ottawa, ON, Minister of Public Works and Government Services Canada.

14. Healy GN, Dunstan DW, Salmon J, Cerin E, Shaw JE, Zimmet PZ, Owen N. Breaks in sedentary time: beneficial associations with metabolic risk. Diabetes Care. 2008;31(4):661-6. 
15. Healy GN, Wijndaele K, Dunstan DW, Shaw JE, Salmon J, Zimmet PZ, Owen N. Objectively measured sedentary time, physical activity, and metabolic risk: the Australian Diabetes, Obesity and Lifestyle Study (AusDiab). Diabetes Care. 2008;31(2):369-71.

16. Kahan D. Relationships among religiosity, physical activity, and sedentary behavior in Jewish adolescents. Pediatr Exerc Sci. 2004;16(1):54-63.

17. Katzmarzyk PT, Baur LA, Blair SN, Lambert EV, Oppert JM, Riddoch C. Expert panel report from the International Conference on Physical Activity and Obesity in Children, 24-27 June 2007, Toronto, Ontario: summary statement and recommendations. Appl Physiol Nutr Metab. 2008;33(2):371-88.

18. Katzmarzyk PT and Tremblay MS. Limitations of Canada's physical activity data: implications for monitoring trends. Can J Public Health. 2007;98 Suppl 2:S185-S194.

19. Levine JA, Eberhardt NL, Jensen MD. Role of nonexercise activity thermogenesis in resistance to fat gain in humans. Science. 1999;283(5399):212-4.

20. Mattocks C, Leary S, Ness A, Deere K, Saunders J, Kirkby J, Blair SN, Tilling K, Riddoch C. Intraindividual variation of objectively measured physical activity in children. Med Sci Sports Exerc. 2007;39(4):622-9.

21. Montoye HJ, Kemper HCG, Saris WHM, Washburn RA. Measuring Physical Activity and Energy Expenditure. Champaign, IL: Human Kinetics; 1996.

22. Nader PR, Bradley RH, Houts RM, McRitchie SL, O'Brien M. Moderate-to-vigorous physical activity from ages 9 to 15 years. JAMA. 2008;300(3):295-305.

23. Pate RR, O'Neill JR, Lobelo F. The evolving definition of "sedentary". Exerc Sport Sci Rev. 2008;36(4):173-8.

24. Peters JC, Wyatt HR, Donahoo WT, Hill JO. From instinct to intellect: the challenge of maintaining healthy weight in the modern world. Obes Rev. 2002;3(2):69-74.

25. Riddoch CJ, Mattocks C, Deere K, Saunders J, Kirkby J, Tilling K, Leary SD, Blair SN, Ness AR. Objective measurement of levels and patterns of physical activity. Arch Dis Child. 2007;92(11):963-9.

26. Shephard RJ. Limits to the measurement of habitual physical activity by questionnaires. Br J Sports Med. 2003;37(3):197-206.

27. Stamatakis E, Ekelund U, Wareham NJ. Temporal trends in physical activity in England: the Health Survey for England 1991 to 2004. Prev Med. 2007;45(6):416-23.

28. Sturm R. Childhood obesity - what we can learn from existing data on societal trends, part 1. Prev Chronic Dis. 2005;2(1):A12.

29. Sturm R. Childhood obesity -- what we can learn from existing data on societal trends, part 2. Prev Chronic Dis. 2005;2(2):A20. 
30. Tremblay MS, Barnes JD, Copeland JL, Esliger DW. Conquering childhood inactivity: Is the answer in the past? Med Sci Sports Exerc. 2005;0(0):00.

31. Tremblay MS, Esliger DW, Copeland JL, Barnes JD, Bassett DR. Moving forward by looking back: lessons learned from long-lost lifestyles. Appl Physiol Nutr Metab. 2008;33(4):836-42.

32. Tremblay MS, Esliger DW, Tremblay A, Colley R. Incidental movement, lifestyleembedded activity and sleep: new frontiers in physical activity assessment. Can J Public Health. 2007;98 Suppl 2:S208-S217.

33. Troiano RP, Berrigan D, Dodd KW, Masse LC, Tilert T, McDowell M. Physical activity in the United States measured by accelerometer. Med Sci Sports Exerc. 2008;40(1):181-8.

34. Trost SG, Pate RR, Sallis JF, Freedson PS, Taylor WC, Dowda M, Sirard J. Age and gender differences in objectively measured physical activity in youth. Med Sci Sports Exerc. 2002;34(2):350-5.

35. Wang YC, Gortmaker SL, Sobol AM, Kuntz KM. Estimating the energy gap among US children: a counterfactual approach. Pediatrics. 2006;118(6):e1721-e1733. 
Table 1. Accelerometry data collection and analytical procedures.

\begin{tabular}{|c|c|}
\hline \multicolumn{2}{|l|}{ General Information } \\
\hline Device & Actigraph \\
\hline Model & 7164 \\
\hline Piezosensor Orientation & Uniaxial \\
\hline Number of Accelerometers Used & 117 \\
\hline Serial Number Range & $11672-23880$ \\
\hline Average Number of Deployments Per & \\
\hline Unit & 4 (ranging from 1 to 9 ) \\
\hline Pre-deployment Calibration Check & Yes \\
\hline Technical Variability Tolerance (CV\%) & $\leq 5 \%$ \\
\hline \multicolumn{2}{|l|}{ Setup Information } \\
\hline Mode & Counts Only \\
\hline Epoch & 1 Minute \\
\hline Deployment Method & Delivered and attached by researcher (on day 0 ) \\
\hline Location Worn & Right hip at mid clavicular line (via adjustable nylon waist belt) \\
\hline Requested Days of Wear & 7 days (i.e., 10080 epochs) not including day 0 \\
\hline Initialization \& Monitor Start Time & Delayed until next day (i.e., day 1 at 06:00) \\
\hline Wear Instructions & During all *waking hours (except water based activities) \\
\hline \multicolumn{2}{|l|}{ Analytical Decisions } \\
\hline Sleep Time Appropriation & $\begin{array}{l}\text { Continuous zeros indicating the start of sleep time were coded by researchers } \\
\text { based on the transition from epochs with normal count data to epochs of } \\
\text { continuous zeros. The accelerometer on time at wake up was marked based on the } \\
\text { first non-zero epoch after the overnight period (informed by the participant's log } \\
\text { sheet). }\end{array}$ \\
\hline Valid Day Criteria & 10 hours of wear \\
\hline $\begin{array}{l}\text { Valid File } \\
\text { Modeling (i.e., imputation) of Missing }\end{array}$ & At least 5 of 7 days (with at least 1 weekend day) \\
\hline Data & None \\
\hline
\end{tabular}


Daylight Saving Time

Cutpoint Reference(s)

\section{Sedentary}

Light Intensity

Moderate Intensity

Vigorous Intensity
Files crossing DST in the fall of 2002 were corrected for the repeat hour For light, moderate, and vigorous intensity, age-specific cutpoints developed by the Freedson group as published by Trost et al. (34) were used. The sedentary cutpoint, although not empirically derived, has been published previously by Mattocks et al. (20).

\section{0-199 counts}

200 counts - 3.99 METs (age specific)

4.0 - 6.99 METs (age specific)

7+ METs (age specific)

*The start and end of the daily accelerometer wear periods was used as a surrogate for sleep time. 
Table 2. Characteristics of the study sample.

\begin{tabular}{|c|c|c|c|c|}
\hline Variable & OOA & OOM & RSK & USK \\
\hline Sample location in Canada & Aylmer, ON & $\begin{array}{l}\text { Waterloo \& } \\
\text { Wellington } \\
\text { County, ON }\end{array}$ & $\begin{array}{l}\text { Clavet, } \\
\text { Colonsay, \& } \\
\text { Hanley, SK }\end{array}$ & $\begin{array}{c}\text { Saskatoon, } \\
\text { SK }\end{array}$ \\
\hline Data collection period & Spring 2005 & Fall 2002 & Fall 2002 & Fall 2002 \\
\hline Original sample & 79 & 120 & 165 & 110 \\
\hline Failed to initialize/collect & 10 & 0 & 8 & 3 \\
\hline Spurious data & 1 & 0 & 6 & 0 \\
\hline Not enough wear time & 0 & 0 & 19 & 14 \\
\hline Viable sample & 68 & 120 & 132 & 93 \\
\hline 7 valid days & $68(100 \%)$ & $120(100 \%)$ & $105(80 \%)$ & $76(82 \%)$ \\
\hline 6 valid days & - & - & $24(18 \%)$ & $15(16 \%)$ \\
\hline 5 valid days & - & - & $3(2 \%)$ & $2(2 \%)$ \\
\hline Average daily wear minutes (SD) & $873(33)$ & $820(27)$ & $805(46)$ & $806(44)$ \\
\hline Average daily non-wear minutes (SD) & $567(33)$ & $620(27)$ & $635(46)$ & $634(44)$ \\
\hline Average morning "on" time (SD) & $06: 38(0: 25)$ & 07:07 (0:26) & $08: 13(0: 31)$ & $08: 30(0: 35)$ \\
\hline Average evening "off" time (SD) & $21: 05(0: 25)$ & $20: 49(0: 22)$ & $21: 28(2: 11)$ & $22: 01(0: 47)$ \\
\hline
\end{tabular}

Note: Non-wear (manually coded by the researcher) was used as a surrogate for sleep 
Table 3. Descriptive characteristics of study participants; mean (SD) and range.

\begin{tabular}{ccccc}
\hline Variable & OOA & OOM & RSK & USK \\
\hline N (\% female) & $68(44)$ & $120(45)$ & $132(57)$ & $93(54)$ \\
Age (yrs) & $10.6(1.74)$ & $11.6(1.26)^{*}$ & $10.9(1.20)$ & $11.1(1.16)$ \\
& $8.0-13.9$ & $9.1-13.8$ & $8.8-13.2$ & $8.8-13.2$ \\
Standing height $(\mathrm{cm})$ & $141.0(11.7)$ & $149.0(9.3)$ & $146.3(10.1)^{\dagger}$ & $146.2(10.3)$ \\
& $119.0-165.0$ & $124.5-174.5$ & $123.5-169.0$ & $122.0-172.0$ \\
Weight $(\mathrm{kg})$ & $35.3(10.2)$ & $44.4(10.1)^{\dagger}$ & $41.2(9.7)^{\dagger}$ & $40.6(9.6)$ \\
& $20.0-73.3$ & $23.5-70.3$ & $21.4-69.5$ & $22.0-67.8$ \\
BMI $\left(\mathrm{kg} \cdot \mathrm{m}^{-2}\right)$ & $17.2(2.6)^{* *}$ & $19.8(3.0)$ & $19.0(2.8)$ & $18.8(2.7)$ \\
& $13.4-31.3$ & $13.2-26.7$ & $11.9-26.2$ & $13.9-25.8$ \\
Triceps skinfold (mm) & $10.8(4.8)^{* *}$ & $16.5(6.8)$ & $17.7(7.2)$ & $18.0(7.5)$ \\
& $5.0-31.7$ & $6.1-33.0$ & $5.2-39.8$ & $5.5-39.4$ \\
Prevalence of overweight (\%) & 3.0 & 28.3 & 23.7 & 18.3 \\
Prevalence of obesity (\%) & 1.5 & 3.3 & 1.5 & 1.1 \\
\hline
\end{tabular}

BMI = body mass index; ${ }^{*}$ significantly different from all other groups; ${ }^{* *}$ significantly different from all other groups when controlling for age; $\uparrow$ significantly different than OOA when controlling for age; $\mathrm{P}<0.05$ 
Figure 1

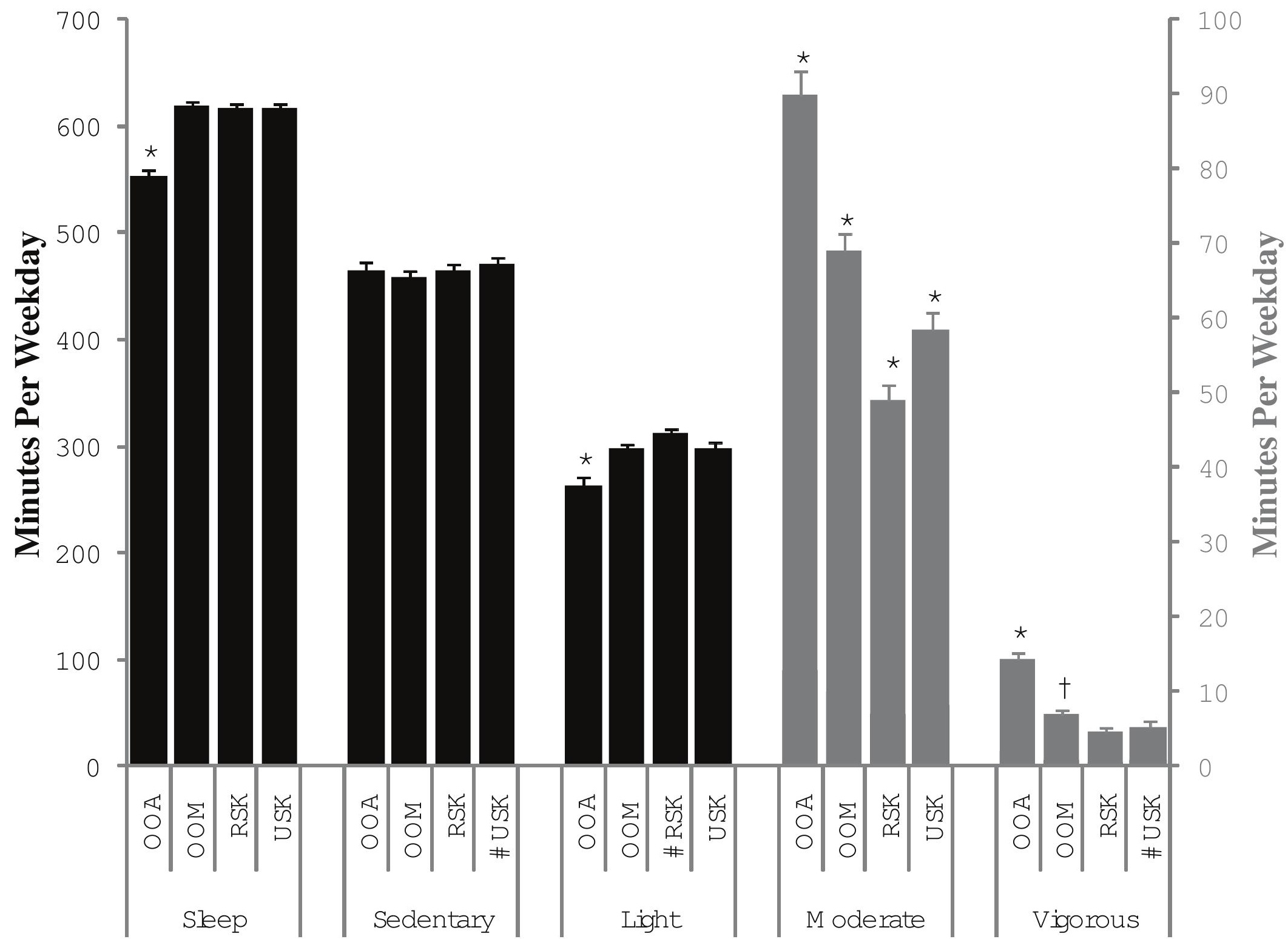


Figure 2

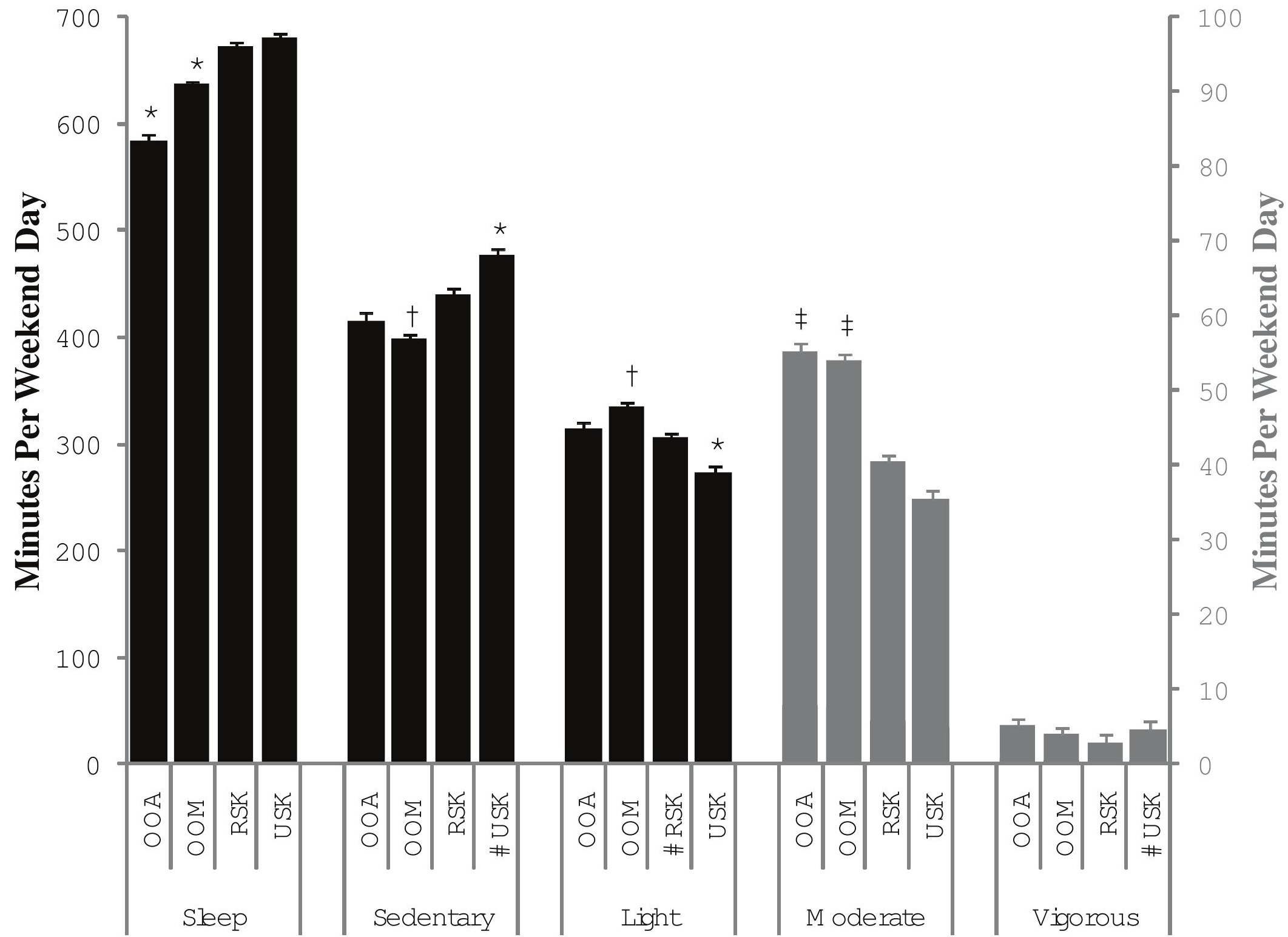



at: http://dx.doi.org/10.1249/MSS.0b013e3181b3afd2
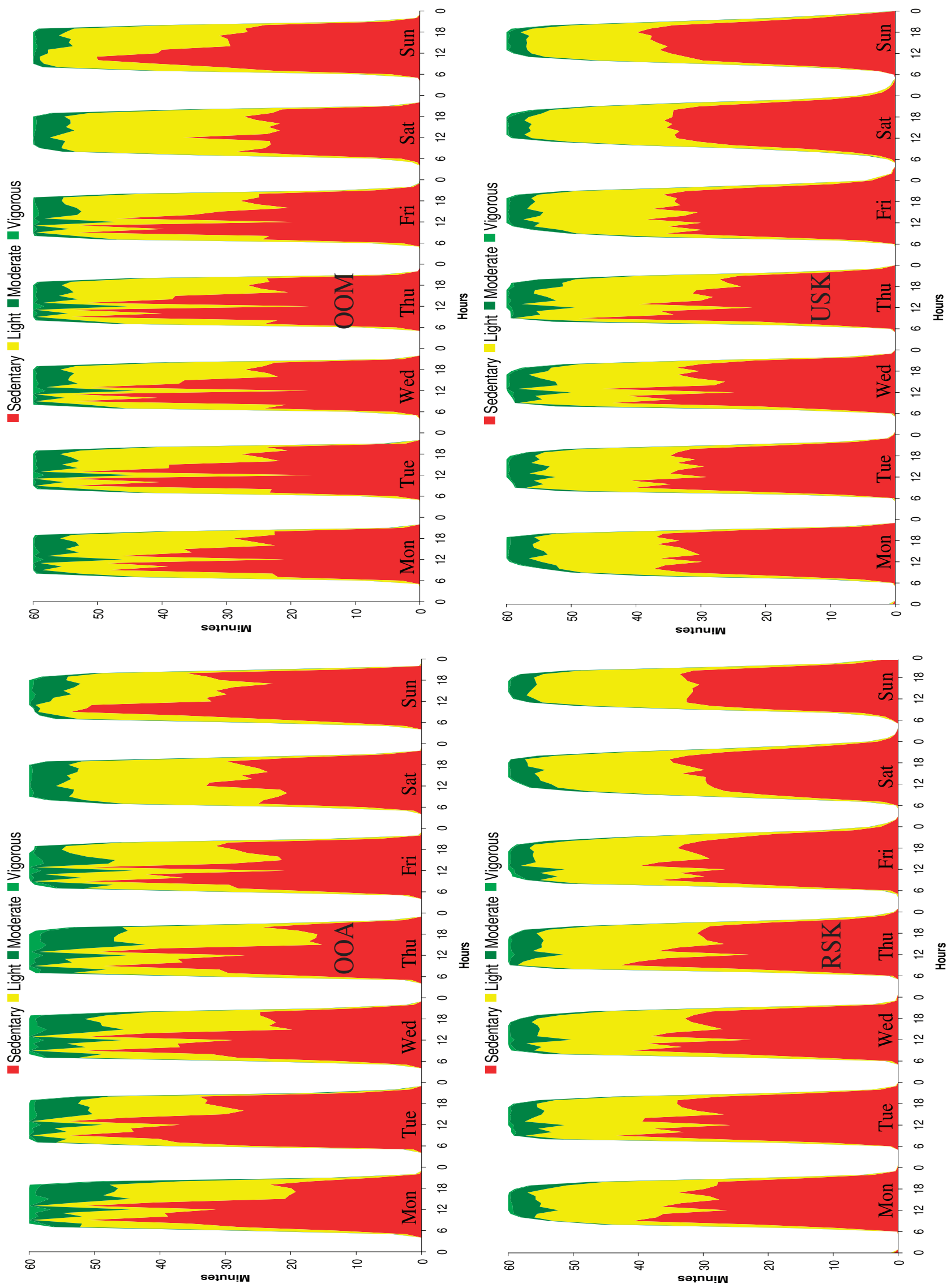

This is a non-final version of an article published in final form in Medicine and Science in Sports and Exercise, 42(2), pp.296-303 
